\title{
Making up symptoms: psychic indeterminacy and the construction of psychotic phenomena
}

\author{
Huw Green
}

BJPsych Bulletin (2019) 43, 81-84, doi:10.1192/bjb.2018.81

Icahn School of Medicine at Mount Sinai, USA

Correspondence to Dr Huw Green (huw.green@gmail.com)

First received 26 Feb 2018, final revision 22 May 2018, accepted 24 Sep 2018

(c) The Author 2018. This is an Open Access article, distributed under the terms of the Creative Commons Attribution-NonCommercial-

NoDerivatives licence (http:// creativecommons.org/licenses/by-ncnd/4.0/), which permits non-

commercial re-use, distribution, and reproduction in any medium, provided the original work is unaltered and is properly cited. The written permission of Cambridge University Press must be obtained for commercial re-use or in order to create a derivative work.
Summary Psychotic phenomena include a far wider range of experiences than is captured by the brief descriptions offered in contemporary diagnostic guides. Given the richness of historical clinical phenomenology, what can account for the recent ascendancy of relatively impoverished descriptions of psychosis? One possible explanation is provided by Hacking's notion of dynamic nominalism, where human categories change over time in tandem with those who they classify. But although dynamic nominalism makes sense of changes in behaviour, it fails to account for change at the level of subjective experience. In this paper, psychotic symptoms are addressed in the light of the indeterminacy of subjective mental content. A naïveintrospectionist approach to mental symptoms assumes that, notwithstanding practical difficulties, such symptoms are reliably describable in principle. Contemporary philosophy of mind challenges this assumption. Lighting upon a verbal description for ineffable phenomena changes their nature, resolving them into new forms.

Declaration of interest None.

Keywords Philosophy; psychotic disorders; history of psychiatry.

\section{Introduction: historical moving targets}

The DSM-5 provides brief descriptions of the central positive psychotic symptoms of delusions, hallucinations and disorganised thought. In this schema, delusions are defined as 'false beliefs' and hallucinations are defined as 'perception-like experiences'. It is to this framework that patients' experiences are matched to make a psychiatric diagnosis. The dissemination of such definitions and criteria has pervaded society's understanding of what psychosis is like. Their influence can now also be seen in the push for the re-description of psychosis in terms not of symptoms, but as 'unusual beliefs' or 'hearing voices'. ${ }^{1}$ However, it is not always clear that delusions are best characterised as beliefs, ${ }^{2,3}$ and auditory hallucinations can include experiences that do not resemble 'hearing' and do not involve voices. ${ }^{4}$

Historically, delusions, to examine just one of these symptoms, were not necessarily defined as beliefs. Tracing the conceptual history of this particular symptom, German Berrios $^{5}$ has argued for the falsity of what he calls the 'received view' that delusions are beliefs, and detailed its emergence. Berrios suggests that historical intellectual processes shape delusions, although it is not clear whether he intends to suggest that this shaping affects only the received clinical view or also the symptom itself. Berrios argues that the received view was in place by the end of the 19th century. However, a more complex picture of delusions can be seen in the work of two prominent psychopathologists of the early 20th century.
In his original description of the features of the group of schizophrenias, Eugen Bleuler's ${ }^{6}$ overview of delusions includes no explicit requirement that they be beliefs. At many points he seems to be describing a wider variety of mental states. Patients with delusions are described as being unconcerned with evidence or reasons for their ideas, "It is just so", and with this he appears to be quite satisfied' (p. 118). Additionally, delusions are described unlike a dogmatically held belief - as sitting comfortably alongside other inconsistent ideas: 'Unconnected or even mutually contradictory ideas can be maintained simultaneously or appear one after the other within a short interval of time' (p. 125). Bleuler includes false statements that might not be held with any conviction: 'A catatonic's bed is a polar bear. "I lay on it and it seemed like a bed, but it was nevertheless a polar bear"' (p. 126). Additionally, Bleuler explicitly extends his description of delusions into cases of non-belief-like states: "The delusions can appear in the form of "hunches," "intuitions," etc., which can persist permanently in their indefinite forms' (p. 135).

Karl Jaspers, in his seminal description of the phenomenon of delusions, ${ }^{7}$ does not speak of them in terms of belief, but rather builds a complex picture through case examples and phenomenological descriptions. For Jaspers, contrary to modern psychological theorists, ${ }^{8,9}$ delusions proper (what Jaspers terms 'primary delusions') are not belief-like inferences that have been made from an anomalous perceptual input, but form part of the direct experience itself. 
Jaspers emphasises the immediacy of a delusional interpretation. A delusional patient sees their delusion in their experience of the world in the same way as 'If I see a knife, I see a tool for cutting, (p. 99). The word 'belief' does not appear in this part of his discussion.

Compare these rich and heterogeneous descriptions with the formal definition of delusions provided in the DSM-5: ${ }^{10}$ 'Delusions are fixed beliefs that are not amenable to change in light of conflicting evidence. Their content may include a variety of themes (e.g., persecutory, referential, somatic, religious, grandiose)' (p. 87). This historical transmogrification of psychotic symptomatology is a curious phenomenon. I suggest that it represents something potentially significant, occurring not only in the literature but also in the patients. Paraphrasing the philosopher of science Ian Hacking (who referred to 'making up people,"ll), I call this 'making up symptoms'.

\section{Dynamic nominalism}

Historical variation in psychiatric presentations has been understood in terms of bidirectional feedback loops between the patient and world that shape the patient's expression of symptoms. ${ }^{12,13}$ Consider the phenomenon Hacking terms 'dynamic nominalism', the process he posits whereby people come to fit the categories they are assigned. A classification or description of people is created on the basis of some observed regularity or classificatory principle (autistic, anorexic, gay). Observations about this classification are then made by academics, journalists, medics and so forth. Because the individuals classified are people, and not rocks or trees, they can become aware of the classification, and of various facts, fashions and stereotypes associated with it. Such knowledge is apt to change people as they behave increasingly in line with the way that they have come to see themselves described. Hacking has suggested that entire disorders ('transient psychiatric illnesses') can be brought into existence by interactive processes he calls looping effects'. ${ }^{12,14}$ Plainly there are hard limits on the influence of looping effects (people cannot, for example, become taller just because they have been classified as belonging to a group that is stereotypically tall), but the more plasticity there is associated with important elements of a classification, the more we might expect looping effects to exert their influence.

Thus, as clinical phenomenologists produce ever more succinct descriptions of psychotic experiences, people may have come to experience themselves as actually having these simpler symptoms. This, in turn, would have changed the psychiatric classification of psychosis, confirming ever more specific and limited definitions of the phenomena at hand. This story is powerful, but - at least in Hacking's telling - it leaves an explanatory gap in between the world and the patient's symptoms. Dynamic nominalism can readily account for changes in historical behaviour (the culturally determined manifestations of psychiatric distress) because we can readily intuit the ways that behaviour can be influenced by expectations. But there is more to psychosis than behaviour. Mental symptoms feel a particular way, and it is intuitive to suppose that the way they feel is a 'bottom-up' result of internal illness processes. We need more detail about how personal mental experiences could be subject to the same sorts of external influence.

We cannot account for symptom variability without appeal to an important but unacknowledged feature of the mental experience: its ethereal nature. Unlike livers and larynxes, subjective conscious experiences can never be directly observed by another person. Moreover, despite our casual intuitive sense that we have direct access to our subjective experience, it can be uncannily difficult to pin that experience down, even for ourselves. Consciousness is messy, inchoate and often ineffable. It may even be that its contents are indeterminate, and even indeterminable.

\section{Psychic indeterminacy}

The indeterminacy of mental content has been perhaps most thoroughly explored by the philosopher Eric Schwitzgebel. ${ }^{15}$ Schwitzgebel articulates scepticism about the possibility of accurate introspection on one's perceptual experiences. We might think that we know what our perceptual experiences are like in some detailed and accurate way. At first blush, what could be more immediately knowable? But subjectivity is often transient and difficult to pin down. We are not always clear whether an impression (the impression, for example, that one is looking at a scene that contains spatial depth) arises from something that is more directly perceptual or more inferential in character. For Schwitzgebel, questions like 'Do you always have a constant tactile experience of your feet in your shoes?' and 'What do you see when your eyes are closed?' are not as readily answerable as they might appear.

Schwitzgebel provides an example of a historical change that he takes to reflect this indeterminate nature of subjectivity. ${ }^{14}$ Multiple researchers examining reports of dreams in the early 20th century found that a minority of respondents' dreams (9-41\%) involved the experience of colour. Since the 1960s, however, that figure changed and research participants reported that the majority of their dreams (74-100\%) included the experience of colour. Schwitzgebel takes this to suggest that 'I don't know, and you probably don't know, whether we dream in color or not' (p. 3), and suggests that the dramatic change in people's assumptions about their dreams reflects the emergence of widespread access to colour television and films. Dreamers changed their assumptions about the nature of visual experiences and translated this into a judgement about the quality of their dreams.

Schwitzgebel's pessimism about the reliability of introspection has obvious implications for the assessment of psychiatric phenomena. If he is right about the unreliability of naïve introspection, then the assessment of experiences like hallucinations and delusions is open to variability and influence. To ask whether someone is hearing voices or whether they believe in a given proposition is doubly problematic. Such queries presuppose that there is a fact of the matter, and create unwarranted certainty as respondents confabulate an account of their subjective impressions.

Something like this indeterminacy of the subjective has already been posited in the realm of psychiatric symptoms. 
Citing Dennett's ${ }^{16}$ scepticism about the possibility of relying on inner experience, Stephens and Graham ${ }^{17}$ note that not all auditory visual hallucinations are voice-like, and suggest that individuals who come to hold certain ideas may sometimes engage in a sort of ad hoc confabulation about their origin. The result of such confabulation might be a conclusion that an idea came to be held because a voice was heard $^{8}$ (pp. 26-31). The psychoanalyst Roy Schafer ${ }^{18}$ has also explored the indeterminacy of psychiatrically relevant symptoms, pointing out that inquiring about certain vague experiences (e.g. the location of a felt mental presence) can alter the nature of the experience itself ${ }^{9}$ (p. 123).

Does this not lead us to phenomenological nihilism? If our mental life is indeterminate, is there any value in asking people about their inner lives? What about asking people whether they are in pain? (I am grateful to an anonymous reviewer for raising this question.) I think we can fruitfully distinguish more or less fine-grained aspects of experience, with greater difficulty attendant on making determinations about more detailed phenomenology. It is relatively straightforward to say, 'I'm in pain', but far more complex to make detailed descriptions of the nature and quality of that pain. Physicians also ask questions like 'is the pain sharp or dull?' or 'is it a shooting pain?'. Some people, lacking a clear idea about how to answer, could have their experience of the pain changed by the question. Equally, it may be possible to establish the presence of a hallucinatory experience, but harder to describe its form without contamination by interrogation.

If subjective experiences are indeterminate in this important way, then there are grounds to worry about the emphasis on specific symptoms in contemporary psychiatry and clinical psychology. Over the latter half of the 20th century, psychiatry saw a push toward more precise measurement of psychiatric phenomena. A loss of confidence in diagnostic categories shifted attention to the observation and measurement of specific symptomatic experiences.

Paradoxically, however, this focus on symptoms (and especially the use of familiar terminology like hearing voices or unusual beliefs as opposed to the vaguer and more clinical hallucinations or delusions) may be taking us further from the individual experience of people in profound states of disturbance. When we ask people whether their experience is like hearing voices, they may be inclined - when confronted with the immense difficulty of describing what it is really like - to accede that it is.

Take a question like 'Do you ever seem to hear noises or voices when there is no one about, and nothing else to explain it?' from Wing et al's Present State Examination. ${ }^{19}$ A person answers yes. In response to the follow-up question ('Do you ever seem to hear your name being called?'), they also say yes. It is possible that this individual does not, in fact, have those experiences (they do not actually hear noises or voices, they experience something else that feels impossible to describe in other terms), and that they do not actually hear their name being called. Perhaps they just have some sense that there are voices or noises in the vicinity that are having some kind of a perceptual effect on them. Perhaps there is a sense in which they are feeling called, but they never actually have the perceptual experience of a voice calling their name.

I have administered this kind of a questionnaire to people, and it is true that they can prompt the interviewee to provide reflections on how, no their experience is not 'quite' like that being described in the question. Interesting discussions about personal phenomenology can ensue. However, people also have difficulties articulating their experience. People have more or less ability to communicate, and more or less interest in getting the nature of their experience precisely articulated ('I don't really hear the voices but, ah, close enough!').

\section{Making up their minds}

The myth of measurable and determinate psychotic symptoms neglects entire aspects of people's experiences and recent research has revealed that some people with psychiatric illness can come to feel alienated by the discipline's failure to encompass the variety of phenomenology. ${ }^{4,19}$ Jones and Shattell ${ }^{20}$ describe the experiences of people who have had psychotic experiences that 'simply did not map onto available terms and constructs' (p. 769). These authors find participants afraid of describing their experiences to doctors in case they were dismissed, and others who had been told there was 'no such thing' as non-auditory voices: 'It was not that the textbooks were wrong...her experiences were $^{, 19}$ (p. 769). Too tight a focus on preordained symptom categories (the core positive symptoms of the DSM-5) omits those experiences that do not readily fit them. Psychiatric symptom erasure is a systematic failure to take seriously an individual's own account of what is happening to them.

But perhaps more fundamentally, the process of making up symptoms unwittingly shapes people to clinician expectations. Anyone is potentially vulnerable to introspective error and this vulnerability is compounded by the frightening, unusual and private nature of a psychotic symptom. The clinicians who assess such experiences ask specific questions and have diagnostic expectations, thereby providing a particular framework for their patients to fit into. It is a mistake to minimise the potential power of such shaping.

In his discussion of multiple personality disorder, ${ }^{12}$ Hacking outlines the moral hazard involved in the inadvertent creation of psychiatric subjectivity by reference to a Marxist concept. To create and impose new ways of being psychiatrically disturbed, he says, is to subject people to a form of false consciousness. If my argument here is correct, we cannot successfully demarcate false from true consciousness. If there is no plain fact of the matter about the nature and contents of mental states to begin with, there is no 'pure' unobserved form of consciousness to compare against a putatively 'false' form. Nonetheless, I submit that Hacking is on to something significant. When psychiatrists come into contact with disturbances of consciousness, they cannot hope to only observe them. The mind is not infinitely malleable (it would salve much therapeutic angst if it were), but encounters with others - especially powerful professional others - can be expected to influence the form that peoples' thoughts can take. 


\section{About the author}

Huw Green is a postdoctoral clinical fellow in psychology at the Icahn School of Medicine at Mount Sinai, New York, USA.

\section{References}

1 Cooke A, Basset T, Bentall R, Boyle M, Cupitt C, Dillon J. Understanding Psychosis and Schizophrenia. British Psychological Society, 2014

2 Currie G. Imagination, delusion and hallucinations. Mind Lang 2000; 15(1): 168-83.

3 Campbell J. Rationality, meaning, and the analysis of delusion. Philos Psychiatry Psychol 2001; 8(2): 89-100.

4 Jones N, Luhrmann TM. Beyond the sensory: findings from an in-depth analysis of the phenomenology of 'auditory hallucinations' in schizophrenia. Psychosis 2016; 8(3): 191-202.

5 Berrios G. Delusions as wrong beliefs: a conceptual history. $\mathrm{Br} J$ Psychiatry 1991; 159: 6-13.

6 Bleuler E. Dementia Praecox or the Group of Schizophrenias. International Universities Press, 1911.

7 Jaspers K. General Psychopathology (Vol. 1). John Hopkins University Press, 1913.

8 Davies M, Coltheart M, Langdon R, Breen N. Monothematic delusions: towards a two-factor account. Philos Psychiatry Psychol 2001; 8(2): $133-58$

9 Coltheart M, Langdon R, McKay R. Delusional belief. Annu Rev Psychol 2011; 62: 271-98.
10 American Psychiatric Association. Diagnostic and Statistical Manual of Mental Disorders (5th edn). American Psychiatric Publishing, 2013.

11 Hacking I. Historical Ontology. Harvard University Press, 2004.

12 Hacking I. The Social Construction of What? Harvard University Press, 1999.

13 Hacking I. Rewriting the Soul: Multiple Personality and the Sciences of Memory. Princeton University Press, 1995.

14 Hacking I. Mad Travelers: Reflections on the Reality of Transient Mental Illnesses. University of Virginia Press, 1998.

15 Schwitzgebel E. Perplexities of Consciousness. MIT Press, 2011.

16 Dennett DC. Consciousness Explained. Little, Brown, 2017.

17 Stephens GL, Graham G. When Self-Consciousness Breaks: Alien Voices and Inserted Thoughts. MIT Press, 2000.

18 Schafer R. Aspects of Internalization. International Universities Press, 1968.

19 Wing JK, Cooper JE, Sartorius N. Present State Examination. Cambridge University Press, 1974.

20 Jones N, Shattell M. Not what the textbooks describe: challenging clinical conventions about psychosis. Issues Ment Health Nurs 2016; 37(10): 769-72. 